\title{
Acute pancreatitis in systemic lupus erythematosus: report of a case unrelated to drug therapy
}

\author{
ROGER WOLMAN ${ }^{1}$ CHRISTOPHER DE GARA, ${ }^{2}$ AND DAVID ISENBERG ${ }^{1}$ \\ From the ${ }^{1}$ Bloomsbury Rheumatology Department and the ${ }^{2}$ Bloomsbury Vascular Unit, The Middlesex \\ Hospital, Arthur Stanley House, Tottenham Street, London
}

SUMmaRY Systemic lupus erythematosus (SLE) is an autoimmune rheumatic disease that can affect most organs or systems. It most frequently involves the joints, skin, and the kidneys. It less commonly involves the central nervous system, heart, and lungs. Acute pancreatitis in SLE is rare. It is usually mild, occurring in association with more severe organ involvement elsewhere. A patient with newly diagnosed SLE is reported who developed acute fulminant pancreatitis unrelated to concomitant drug therapy and who eventually died of complications including a systemic fungal infection related to this.

Key words: fungal infection.

\section{Case report}

A 25 year old Caucasian woman presented with a two month history of lethargy, fever, and arthralgia. Six months before presentation she had developed Raynaud's phenomenon.

On admission, examination showed a low grade pyrexia $\left(37.6^{\circ} \mathrm{C}\right)$, an erythematous, blotchy facial rash, mouth ulceration, and generalised lymphadenopathy. There was no hepatosplenamegaly. She had fusiform swellings of the fingers with tenderness over the metacarpophalangeal and proximal interphalangeal joints. There was widespread muscle tenderness.

Laboratory investigations included the following results: haemoglobin $85 \mathrm{~g} / 1$ (normochromic, normocytic), white blood cell count (WBC) $4 \cdot 1 \times 10^{9} / 1$, erythrocyte sedimentation rate $51 \mathrm{~mm} / \mathrm{h}$, urea, electrolytes, and creatinine clearance normal; serum aspartate transaminase 520 IU/1 (normal 9-40), alanine transaminase 132 IU/l (normal 7-45), alkaline phosphatase 195 IU/l (normal 35-105), corrected calcium normal, creatinine phosphokinase 702 U/l (normal 24-195); immunoglobulins

Accepted for publication 15 June 1987.

Correspondence to Dr Roger Wolman, British Olympic Medical Centre, Northwick Park Hospital, Harrow, Middlesex HA1 3UJ. normal, RAHA and latex titres negative, positive antinuclear antibody titre 1/160 (diffuse, speckled), double stranded DNA antibodies negative by the Crithidia test, an unidentified line only on testing for antibodies to the extractable nuclear antigens, but antiribosomal antibodies positive $1 / 80$, lupus anticoagulant positive (KPPT patient $=58 \mathrm{~s}$, control $=39$ $\mathrm{s}, \mathrm{mix}=48 \mathrm{~s}$ ), lupus band test positive.

A diagnosis of SLE was made. On the 10th day of admission she developed a urinary tract infection and treatment was started with ampicillin. Her only other medication at this time was diclofenac. Two days later, before specific treatment of SLE was started, she developed acute abdominal pain and vomiting with epigastric tenderness. Investigations showed an amylase $3457 \mathrm{IU} / \mathrm{l}$ (normal 70-300), alkaline phosphatase $2900 \mathrm{IU} / \mathrm{l}$, and an abdominal ultrasound showing a normal biliary tree and a diffusely enlarged pancreas consistent with acute pancreatitis. Her WBC was $6.9 \times 10^{9} / \mathrm{l}$, glucose $6.0 \mathrm{mmol} / \mathrm{l}$, and corrected calcium $2.07 \mathrm{mmol} / \mathrm{l}$.

She was transferred to the intensive therapy unit as there was evidence of both impending renal and respiratory failure. Her urine output remained low despite correction of the central venous pressure and the use of dopamine.

Blood gases showed hypoxia and hypocapnia. Chest $x$ ray showed widespread patchy shadowing, 
while the pulmonary capillary wedge pressure was normal. It was therefore assumed that she had adult respiratory distress syndrome (ARDS), and she was electively ventilated.

Despite maximum supportive therapy over the next 48 hours the acute pancreatitis remained severe as shown by the low serum corrected calcium of about $1.4 \mathrm{mmol} / \mathrm{l}$, persistent metabolic acidosis, and gradually rising urea and creatinine.

It was assumed that the acute pancreatitis was secondary to the SLE. She was therefore given intense immunosuppression with $1 \mathrm{~g}$ cyclophosphamide and $1 \mathrm{~g}$ methylprednisolone intravenously daily for two consecutive days. This made little difference to her clinical status and there was further deterioration in both respiratory and renal function. Six days after the onset of acute pancreatitis she died from a cardiorespiratory arrest.

A postmortem examination showed acute pancreatitis but with no evidence of vasculitis affecting the pancreas. Histology of lung tissue showed widespread haemorrhage in the alveolar spaces with numerous fungal hyphae. There was also evidence of fungal infiltration into both kidneys.

\section{Discussion}

Acute pancreatitis in SLE is uncommon. The association was first described by Reifenstein in $1939 .^{1}$ Since that time there have been about 60 case reports of this association. ${ }^{2-15}$ In only very few could SLE be incriminated as the sole aetiological factor. ${ }^{8}{ }^{12-14}$ In most, a steroid, azathioprine, or diuretic induced pancreatitis could not be excluded. Furthermore, life threatening acute pancreatitis is unusual. In 1958 Pollack et al described three patients who died and were examined after death. ${ }^{3}$ In one the pancreas was involved by an arteritis. In the second the small arteries and arterioles were occluded by thrombus. In the third case the acute pancreatitis was noted in association with end stage renal failure. In 1953 Dubois reported arteritis in the pancreas. $^{2}$ A similar appearance was noted by Seifert $e$ al in $1967 .{ }^{4}$ Our case is thus unusual, firstly because pancreatitis ${ }^{14}$ occurred very soon after the onset of SLE, making it easier to exclude other aetiological factors, and secondly because of its severity.

The rapid deterioration despite intense immunosuppression in this case raises two main issues. Firstly, what was the aetiology of the acute pancreatitis, and secondly, the dangers of attributing impaired respiratory function in the acutely ill to ARDS.

Our patient's clinical features on presentation, her autoantibody profile, the presence of the lupus anticoagulant, and the positive lupus band test leave us in no doubt that she had SLE. The aetiology of the acute pancreatitis is less certain, however.

The common causes of acute pancreatitis were excluded (no history of alcohol abuse, no evidence of gall bladder disease before or after death, and n\& serological evidence of a viral illness). This leave\& three unusual possible causes of acute pancreatitis. - namely, drug, fungal, or SLE.

The only drugs being taken at the onset of acute pancreatitis were diclofenac and ampicillin. Despite widespread use neither drug has been associatecô with this condition. ${ }^{16}$ Furthermore, we are unaware of any case reports of acute pancreatitis secondary to fungal infection. This therefore makes SLE the most likely aetiological factor. Unfortunately at the postmortem examination the pancreas was auto lysed making it impossible to confirm the aetiolog $\vec{y}$ of the pancreatitis.

About $20 \%$ of patients who develop acute pan creatitis have severe disease and within this group the mortality is between $20 \%$ and $40 \% .{ }^{17}$ Out patient was clearly in the poor prognosis category a $0^{\circ}$ previously defined,$^{18}$ and ARDS is a well recognised complication of this. She therefore required inten sive care supportive measures. Additional measureswere considered but treatment with the anti proteinase aprotinin, ${ }^{19}$ peritoneal lavage, ${ }^{20}$ anc early pancreatic surgery ${ }^{21}$ have shown no cleap benefit and were not used. It was felt that we should $\vec{b}$ treat what was thought to be the underlying cause of the pancreatitis, namely SLE, with intense immuno suppression.

Within a few hours of making the diagnosis of acute pancreatitis the patient's blood gases were abnormal with a low $\mathrm{Po}_{2}$ and a low $\mathrm{PcO}_{2}$. Chest $x$ ray . showed diffused mottling in the lung fields consis tent with ARDS. After initiating intense immunosuppression there was further deterioration in the blood gases and this was also assumed to be due to ARDS. Given that she had acute pancreatitis theres were no specific pointers to suggest that she had a. coexisting pneumonia and septicaemia and this onlyo became apparent at necropsy. This case reiterates the need to have a low threshold for considering coexisting opportunistic infection in patients in the intensive therapy unit and the necessary investigations thereof.

\section{References}

1 Reifenstein E C, Reifenstein E C Jr, Reifenstein G H. A variable symptom complex of undetermined etiology with fataP termination. Arch Intern Med 1939; 63: 553-74.

2 Dubois E L. The effect of the LE cell test on the clinical picture of SLE. Ann Intern Med 1953; 38: 1265-94.

3 Pollack V E, Grove W J, Kark R M, Muehrcke R C. SLEO simulating acute surgical condition of the abdomen. $N$ Engl $J$ Med 1958; 259: 258-66. 
4 Seifert G, Heinz N, Ruffmann A. Pancreatitis in visceral lupus erythematosus. Gastroenterologia (Basel) 1967; 107: 317-27.

5 Sparberg M. Recurrent acute pancreatitis associated with SLE. American Journal of Digestive Diseases 1967; 12: 522-6.

6 Mekori Y A, Yaretzky A, Schneider M, Klajman A. Pancreatitis in SLE-a case report and review of the literature. Postgrad Med J 1980; 56: 145-7.

7 Baron M, Brisson M L. Pancreatitis in SLE. Arthritis Rheum 1982; 25: 1006-9.

8 Reynold J C, Inman R D, Kimberly R P, Chuong J H, Kovacs J E, Walsh M B. Acute pancreatitis in SLE: report of 20 cases and a review of the literature. Medicine (Baltimore) 1982; 61: 25-32.

9 Croft S M, Jarrett M P, Craig R, Perlman S G. Pancreatitis and SLE: a case report. Arthritis Rheum 1983; 26: 238-9.

10 Martini A, Notarangelo L D, Barberis L, Plebani A. Pancreatitis in SLE. Arthritis Rheum 1983; 26: 1173.

11 Ossi E, Fiocco U, Belloni M, et al. Therapy of acute pancreatitis in SLE with plasmapheresis and corticosteroids. Clin Exp Rheumatol 1983; 1: 345-7.

12 Zanen S, Brandi A, Cats A. Acute pancreatitis in SLE; successful treatment with plasmapheresis after failure of prednisolone. Clin Exp Rheumatol 1983; 1: 341-4.

13 Marino C, Lipstein-Kresch E. Pancreatitis in SLE. Arthritis Rheum 1984; 27: 118-9.
14 Giordano M, Gallo M, Chianese U, Maniera A, Tirri G. Acute pancreatitis as the initial manifestation of SLE. $Z$ Rheumatol 1986; 45: 60-3.

15 Brujin J A, Van Albada-Kuipers G A, Smit V Th H B M, Eulderink F. Acute pancreatitis in SLE. Scand $J$ Rheumatol 1986; 15: 363-7.

16 Bourke J B, Mclllmurray M B, Mead G M, Langman M J S. Drug-associated primary acute pancreatitis. Lancet 1978; i: 706-8.

17 Imrie C W, Shearer M. Diagnosis and management of severe acute pancreatitis. In: Russell R C G, ed. Recent advances in surgery. Vol 12. Edinburgh: Churchill Livingstone, 1986: 143-54.

18 Ranson J H C, Pasternack B S. Statistical methods for quantifying the severity of clinical acute pancreatitis. J Surg Res 1977; 22: 79-91.

19 Imrie C W, Benjamin I S, Ferguson J C, et al. A single centre double blind trial of Trasylol therapy in primary acute pancreatitis. Br J Surg 1978; 65: 337-41.

20 Mayer A D, McMahon M J, Corfield A P, et al. Controlled clinical trial of peritoneal lavage for the treatment of severe acute pancreatitis. $N$ Engl J Med 1985; 312: 399-404.

21 Kivilaakso E, Fraki O, Nikki P, Lempinen M. Resection of the pancreas for acute fulminant pancreatitis. Surg Gynecol Obstet 1981; 152: 493-8. 